Review article

\title{
Cell-free nucleic acids in urine as potential biomarkers of kidney disease
}

\author{
Marianna Gyurászováa , Alexandra Kovalčíkováa , Janka Bábíčkováa,b , Július Hodosy a,c,* , \\ Ľubomíra Tóthováa \\ ${ }^{a}$ Comenius University in Bratislava, Faculty of Medicine, Institute of Molecular Biomedicine, Bratislava, Slovak Republic \\ ${ }^{\mathrm{b}}$ University of Bergen, Faculty of Medicine, Department of Clinical Medicine, Bergen, Norway \\ ${ }^{\mathrm{c}}$ University Hospital Bratislava, Emergency Department Ružinov, Bratislava, Slovak Republic
}

\section{A R T I C L E I N F O}

\section{Article history:}

Received 7 June 2017

Accepted 17 January 2018

Available online 9 February 2018

\section{Keywords:}

Extracellular DNA

Chronic kidney disease

Extracellular vesicles

DNase I

Transrenal nucleic acids

\begin{abstract}
A B S T R A C T
Kidney and uropoetic system diseases represent a major social, economic and health burden. This is mainly because early diagnosis of kidney dysfunction is currently unavailable, since the current markers are often reliably increased only after advanced progression of the renal diseases. Recently, circulating nucleosomes, DNA and numerous forms of RNA have been detected in human biological fluids, such as plasma, urine, saliva, and breast milk. Although their biological functions remain mostly unknown, they are attractive as potential biomarkers of various diseases. In urine, many of the circulating nucleic acids originate from the cells of the kidney and the urinary tract making these non-invasive and easily obtained new biomarkers in the nephrology or urology. This review focuses on cell free nucleic acids in urine and its potential in human studies. Although, there are some technical and biological limitations, the urinary circulating nucleic acids hold a great potential as new biomarkers of renal diseases.
\end{abstract}

(c) 2018 Faculty of Health and Social Sciences, University of South Bohemia in Ceske Budejovice. Published by Elsevier Sp. z o.o. All rights reserved.

\section{Introduction}

Nucleic acids that are not contained within cells are commonly referred to as circulating nucleic acids (CNA). They were first described in 1928, when they were observed to transmit pathogenicity from heat-killed to viable bacteria (Griffith, 1928). The presence of CNA in the circulation was first reported in 1948 by Mantel and Metais in Comptes Rendus de l'Académie des Sciences, Paris. The discovery was not taken seriously until high concentrations of CNA were detected in the blood of patients with systemic lupus erythematosus in 1966 (Tan et al., 1966).

CNA was already isolated from almost all biological fluids, including plasma, serum, saliva, urine, milk and bronchial lavage (O'Driscoll, 2007). It is generally accepted that CNA circulates in measurable amounts in both healthy individuals, and in patients with various diseases. Leon et al. (1977) detected significantly higher concentrations of CNA in the serum of patients with different types of cancer when compared to healthy individuals. They also showed that the concentrations of CNA decreased after patients were successfully cured (Leon et al., 1977; Mittra et al., 2012). This pointed at tumour-derived DNA to be one of the major sources of CNA in cancer patients (Chan et al., 2003). But the existence of CNA was not only found to be interesting for the field of oncology. Lo et al. (1997) were the first to demonstrate that the fetal DNA is circulating in maternal plasma and serum during pregnancy. Also, a fraction of CNA in plasma of transplanted patients has been shown to be of donor origin. This form of DNA chimerism proved to be useful in the monitoring of allograft rejection (Lo et al., 1998). DNA from infectious agents was also found to be a source of CNA. DNA from Plasmodium sp. has been detected in the plasma of patients with malaria (Gal et al., 2001). Inflammation related to overtraining of professional athletes was

Abbreviations: CNA, circulating nucleic acids; SAP, serum amyloid P component; EVs, extracellular vesicles; MVB, multivesicular body; mRNA, messenger RNA; miRNA, micro RNA; lncRNA, long non coding RNA; mtDNA, mitochondrial DNA; DAMPs, damage-associated molecular patterns; NETs, neutrophil extracellular traps; AKI, acute kidney injury; scaRNAs, small Cajal body-specific RNAs; snoRNAs, small nucleolar RNAs; snRNAs, small nuclear RNAs; piRNAs, Piwi-interacting RNAs; COX3, cyclooxygenase 3; ND1, nicotinamide adenine dinucleotide (NADH) dehydrogenase subunit-1; eGFR, estimated glomerular filtration; NGAL, neutrophil gelatinase-associated lipocalin; B7-1, type I membrane glycoprotein; RCC, renal cell carcinoma; B-FABP, brain type fatty acid binding protein; UCA1, urothelial carcinoma associated 1.

* Author for correspondence: Comenius University in Bratislava, Faculty of Medicine, Institute of Molecular Biomedicine, Sasinkova 4, 81108 Bratislava, Slovak Republic.

E-mail address: julius.hodosy@fmed.uniba.sk (J. Hodosy). 
also linked with increased concentrations of plasma CNA (Fatouros et al., 2006). A direct relationship between acute traumatic tissue injury and plasma CNA concentration has been further established. Acute stroke followed by neuron damage can release DNA into the peripheral blood. It has been reported that plasma DNA concentration strongly correlates with the severity of stroke. This finding can be useful in risk stratification of acute stroke patients (Lo et al., 2000; Rainer et al., 2003). Increased plasma CNA, released from apoptotic/necrotic adipocytes, has also been reported in obesity. It has been hypothesized that this CNA released from adipocytes has a leading role in the development of chronic adipose tissue inflammation and insulin resistance in obesity (Nishimoto et al., 2016). As can be seen from the above-mentioned examples, CNA can provide an effective tool for diagnostics of many pathological states. In this review, we provide an overview of extracellular nucleic acids, their origins, and structure with the emphasis on urinary CNA and early diagnostics of renal diseases.

\section{The origin of circulating nucleic acids}

There are various origins and forms of CNA. Circulating nucleosomes, naked DNA, several types of RNA, and mitochondrial DNA have all been detected in plasma, serum and other biological fluids (Peters and Pretorius, 2011). Both passive and active releases of CNA have been described.

Two main sources of these CNA have been proved: the first is a "passive" way, in which CNA as fragments of DNA are released during apoptosis and necrosis. The other, "active" way assumes an active metabolic secretion of DNA from live cells into the extracellular space and biological fluids (Gahan et al., 2008). Both theories had supporters in the field of CNA research, and at this point, it can be stated that both seem to be correct.

Between $10^{11}$ and $10^{12}$ cells divide daily in the human body and the same number goes through apoptosis, to maintain homeostasis. They leave behind 1-10 g of DNA debris per day, and some of this fragmented DNA and nucleosomes may escape cleavage mechanisms. During necrosis, intact DNA can escape fragmentation, as necrosis does not involve intranucleosomal degradation. However, it has been shown that the necrotic pathway is not a major contributor to CNA release (Jahr et al., 2001; van der Vaart and Pretorius, 2008). Terminal differentiation is also a passive source of CNA, as the final stages of the differentiation of erythrocytes, keratinocytes, and lens crystalline cells. In these, the extrusion of nuclear material from the cell occurs (Appleby and Modak, 1977; Scher and Friend, 1978; Terada et al., 1978; Weil et al., 1999).

The active release of DNA by living cells in vitro was firstly described by Anker et al. (1975). It has also been shown that viral DNA circulates in the plasma of patients with cancers associated with the viral infections. In nasopharyngeal carcinoma patients, DNA from Epstein-Barr virus can be detected in $96 \%$ of cases, and human papilloma virus DNA is present in $50 \%$ of patients with cervical cancer. Thus, viral DNA represents an additional source of CNA (Lo et al., 1999a,1999b; Raptis and Menard, 1980; Yang et al., 2004).

Under normal circumstances, pure forms of nucleic acids circulating freely in plasma are degraded because of plasma and serum endonucleases. CNA circulate in complexes with proteins and lipids that protect them from degradation (Fleischhacker et al., 2011). In plasma, several enzymes are actively degrading DNA, such as deoxyribonuclease I, deoxyribonuclease II, phosphodiesterase I and DNA hydrolysing autoantibodies. The most active is deoxyribonuclease I in plasma. (Frittitta et al., 1999; Nadano et al., 1993; Shuster et al., 1992; Yasuda et al., 1992). The fact that DNase has been shown to be inhibited in tumours can partially explain why patients with tumours have higher concentrations of plasma
CNA. In these cases, it is possible for free DNA to circulate with lesser protection (Cooper et al., 1950; Tamkovich et al., 2006). DNA segments, which circulate in the form of nucleosomes (DNA wrapped around histone protein cores), are partially protected against degradation. However, the half-life of the nucleosomes that are injected intravenously is the same as the half-life of fetal DNA in maternal plasma (Gauthier et al., 1996; Lo et al., 1999a,1999b).

Another form of protection for DNA is serum amyloid $P$ component (SAP), a $25 \mathrm{kDa}$ pentametric serum protein, which is able to bind to nucleosomes by replacing histone $\mathrm{H} 1$. It then proceeds to protect DNA from degradation by nucleases and makes nucleosomes soluble in plasma (Pepys and Butler, 1987).

Apoptotic bodies are another source of CNA in the plasma. Apoptotic bodies contain DNA or RNA, and are formed during apoptosis. DNA is cleaved, and the cell and the nucleus are segmented into small uneven pieces and wrapped in membranes. They can escape phagocytosis by macrophages and appear in the plasma as CNA. It has been shown that SAP can bind apoptotic bodies as well (Bickerstaff et al., 1999; Halicka et al., 2000).

Small intracellularly generated extracellular vesicles (EVs) may contain nucleic acid cargo, which is protected from degradation. These include smaller exosomes ranging from $30 \mathrm{~nm}$ to $100 \mathrm{~nm}$ in diameter, and larger microvesicles sized between $100 \mathrm{~nm}$ and $1000 \mathrm{~nm}$. Exosomes are released by a cell when a late endosome, also called a multivesicular body (MVB), fuses with the plasma membrane and releases its contents. Microvesicles differ from exosomes in biogenesis: they arise by the outward budding and fission of the plasma membrane (Akers et al., 2013). These vesicles play a role in intercellular communication and have been implicated in many processes, such as tumour progression or angiogenesis. Recently, it was shown that their cargo may include a set of nucleic acids. EVs have been found to contain messenger RNA (mRNA), microRNA (miRNA), long non-coding RNA (lncRNA) - and mitochondrial DNA ( $m$ tDNA). Exosomal mRNA can be translated in target cells, representing a way of intercellular communication. Exosomes derived from tumour cells have been reported to carry whole genomic dsDNA from the parental tumour cells (Gezer et al., 2014; Guescini et al., 2010; Montecalvo et al., 2012; Thakur et al., 2014; Urbanelli et al., 2015; Valadi et al., 2007).

Tumour associated circulating RNA was first described in the plasma of cancer patients by Kopreski et al. (1999). Since then, mRNA and miRNA were both found circulating in the plasma of healthy subjects and patients. miRNAs are a 19-23 nt long molecules responsible for the post-transcriptional regulation of gene expression. They were first detected in human plasma by Chim et al. (2008). Later, it was found that miRNA specific for placenta was present only in pregnant women and disappeared after delivery (Chim et al., 2008). miRNAs are highly stable in plasma and they can withstand RNase attacks. They occur mostly in lipid or protein complexes, or in vesicles, such as apoptotic bodies, exosomes or microvesicles. They were also found to be associated with ribonucleoprotein complexes and in association with argonaute proteins (Arroyo et al., 2011; Turchinovich et al., 2011; Wang et al., 2010).

mtDNA circulating in the plasma was firstly described by Chiu et al. (2003). Under physiological conditions, mtDNA is present inside the mitochondrial matrix. When a mitochondrial injury occurs, mtDNA fragments, also known as mitochondrial DAMPs (damage-associated molecular patterns) can escape to cytosol and enter systemic circulation (Wenceslau et al., 2014). Patients suffering from age-related neurodegenerative disorders have shown that mtDNAs in human plasma exist as the particleassociated and free state. mtDNA has also been described in exosomes and in relation to neutrophils (Mehra et al., 2007; Tsai et al., 2011; Zachariah et al., 2008). Circulating mtDNA has been reported in relation to various pathologies, e.g. higher 
concentrations were found in patients suffering from granulomatosis with polyangiitis than in healthy controls. On the other hand, a significant increase in the genomic fragment was observed as well (Surmiak et al., 2015).

Another source of CNA is a specific cell dead called NETosis. Activated neutrophils release fiber traps, named neutrophil extracellular traps (NETs) during NETosis. The main components of NETs are decondensed chromatin, histones, and antimicrobial proteins e.g. neutrophil elastase or myeloperoxidase, and also some cytoplasmic proteins (Brinkmann et al., 2004). Most NETs contain nuclear DNA, but a mechanism of mtDNA released in NETs has been described lately (Yousefi et al., 2009). NETosis, can be either "suicidal" or "vital", depending on the survival of the cell. Suicidal NETosis has been described as a novel form of cell death, while a vital NETosis is characterized by a rapid, vesicular secretion of NETs (de Buhr and von Köckritz-Blickwede, 2016). NETosis occurs as a response to activation of neutrophils, induced by either chemical (e.g. chemokines or LPS) or cellular stimuli (inflammatory cells). It has been shown that NETs are likely to contribute to CNA in diverse infectious, non-infectious and autoinflammatory conditions, and in response to acute exercise (Beiter et al., 2015). The involvement of NETs have been documented during sepsis (Clark et al., 2007; McDonald et al., 2012), myocardial infarction (de Boer et al., 2013), pre-eclampsia (Gupta et al., 2006), asthma (Dworski et al., 2011), cystic fibrosis (Dwyer et al., 2014), or cancer (Demers et al., 2012).

It can be concluded that nucleic acids are released into human biological fluids both by active secretion and during various forms of cell death. Their presence is physiological, but changes in their concentration are often associated with pathological states.

\section{The size of circulating nucleic acids}

The structure of freely circulating DNA is double stranded, as was described by Anker et al. (1975). CNA size distribution has been shown to range from 180 to $10,000 \mathrm{bp}$, but most frequently, the observed fragments fall between 180 and $1000 \mathrm{bp}$. The electrophoretic separation of CNA resembles the separation of a molecular weight marker. The ends of DNA fragments are usually capped (Anker et al., 1975; Jahr et al., 2001; Stroun et al., 1987, 1989). As necrotic cells release longer DNA segments $(10,000 \mathrm{bp}$ and longer), this structural standpoint also shows that necrosis is likely only a minor source of CNA. During apoptotic intranucleosomal DNA fragmentation, DNA is firstly cleaved to 50$300 \mathrm{~kb}$ long fragments, and subsequently fragmented into multiple nucleosomal units of 180-200 bp (Holdenrieder and Stieber, 2004; Nagata, 2005; Nagata et al., 2003). Newly synthesized DNA spontaneously released by cells has also shown to be lower in molecular weight than typical genomic DNA fractions. Thus, the size of newly synthesized DNA is similar to CNA size, which is between 180 and $1000 \mathrm{bp}$ (Li and Steinman, 1989). Spontaneously released DNA is associated with an RNA fraction along with a glycoprotein complex. The glycoprotein complex contains a DNAdependent DNA-polymerase and a DNA-dependent RNA-polymerase (Anker et al., 1976; Rogers et al., 1972; Stroun and Anker, 1972). This complex protects DNA from degradation. It can also be taken up by cells that integrate it into their chromatin and express it. In frogs, CNA released by bacteria, can cross the blood-brain barrier and exhibit its biological activity. A study by Adams and Macintosh (1985) described the uptake of newly synthesized ${ }^{3} \mathrm{H}$-thymidinelabeled DNA released from one batch of chick embryo fibroblasts by a different batch of chick embryo fibroblasts. These findings sparked an interest in oncologists, and experiments with tumour cell lines followed. Further research showed that DNA released by localised tumour cells can travel to distant parts of the organism and can be taken up by cells and exert its biological activity. This mechanism was also described to lead to the formation of metastases (Adams et al., 1997; Anker and Stroun, 1972; Gahan et al., 2003; García-Olmo et al., 2004).

\section{Urinary CNA}

As different forms of nucleic acids have been detected in urine, questions about its origin emerged. One of the likely explanations is their transrenal, plasmatic origin, which means that they are cleared from circulation via the kidneys and the urinary tract. Apart from that, the CNA can get into the urine postrenally, i.e. from the cells of the kidneys and the urinary tract, or by microvesicles (Fig. 1). Both genomic and mitochondrial DNA are present in urine. Specific forms of RNA, namely mRNA, miRNA and lncRNA have also been detected in urine. All these urinary CNA have the potential to become biomarkers of certain diseases.

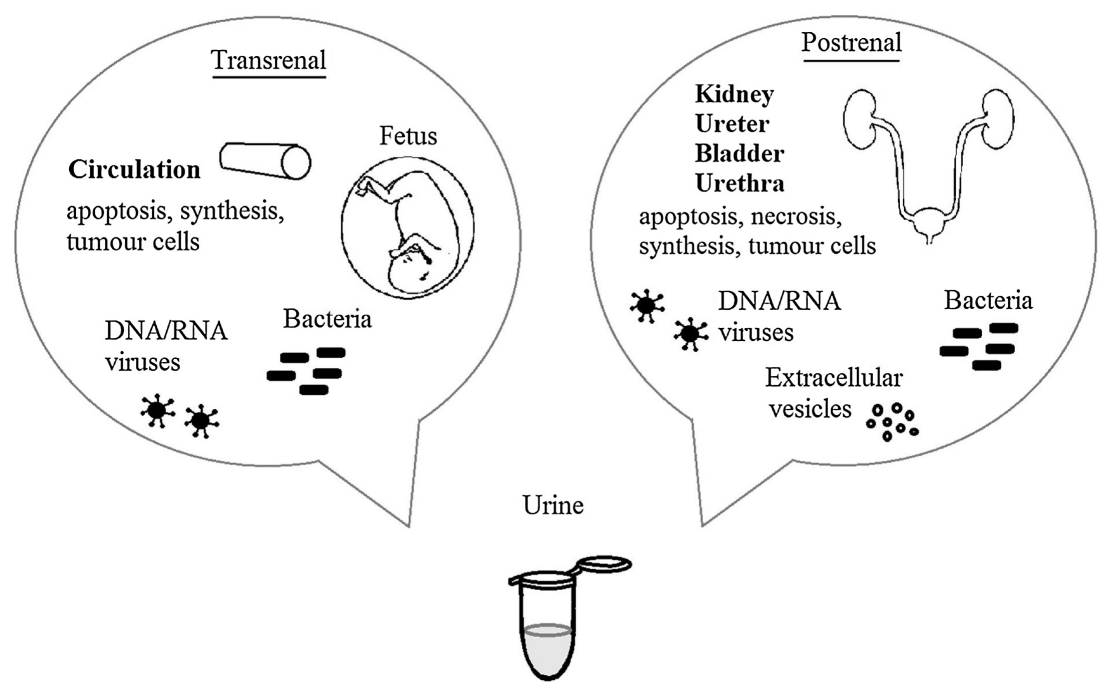

Fig. 1. Sources of cell-free nucleic acids found in urine. Transrenal CNA get into the urine from the circulation via renal clearance. Postrenal CNA originate from the kidneys/ urinary tract. 


\section{Transrenal DNA}

CNA are cleared rapidly from the bloodstream, between 4 and $30 \mathrm{~min}$ (Garcia Moreira et al., 2006). It has been shown that the kidneys play a part in the clearance of DNA from the plasma. However, it should be noted that CNA removal is performed mainly by the liver (Botezatu et al., 2000; Lo et al., 1999a,1999b). Botezatu et al. (2000) reported that a proportion of the DNA excreted into urine comes at sizes that are detectable. Such urinary DNA can be used as a non-invasive, easily accessible genetic material suitable for genetic analysis. Also, it was showed that mice injected with purified bacteriophage DNA and irradiated Raji cells excrete the injected DNA in detectable amounts. In addition, the presence of male DNA in the urine of women transfused with male blood and in pregnant women carrying a male fetus was described (Botezatu et al., 2000). Moreover, tumour-associated K-ras mutations in the urine of patients with pancreatic and colorectal carcinoma were described (Botezatu et al., 2000). These results indicate that nucleic acids detectable in the urine are of plasmatic origin, at least partially.

\section{Postrenal DNA}

Urinary DNA can also originate from epithelial cells of the ureter and other urinary organs called a postrenal way. Also, the lymphocytes and white blood cells can be the source of urinary DNA as well as bacterial infections (Sharma et al., 2011). It is accepted that there is a size limit on the DNA fragments that can enter the urine from a normally functioning kidney: $70 \mathrm{kDa}$, which corresponds to approximately 100 bp DNA fragments in size. Complexes with a higher molecular weight cannot enter the nephron lumen via the filtration barrier (Lote, 2000). This makes it highly unlikely that nucleic acids protected by membranes like exosomes or microvesicles can pass through the kidney barrier and into the urine. On the other hand, exosomes and CNA carried by exosomes have already been identified in urine. The probable explanation is that these EVs are released postrenally, by epithelial cells, including podocytes, renal tubule cells and the transitional epithelial cells lining the urinary drainage system, passed through the renal tubule and collected in the collecting duct (Fang et al., 2013).

Pisitkun et al. (2006) first described exosomes in urine as small vesicles orientated 'cytoplasmic-side inward'. At first, it was thought that the main role of urinary exosome excretion was the elimination of senescent proteins as this way of protein disposal might be more effective than their degradation by lysosomes and proteasomes. This process works to mature red blood cells when they shed membrane proteins and remodel their plasma membrane (Johnstone et al., 1991; van Balkom et al., 2011). But since then, it has been suggested that they might have more elaborate functions than exocytic cell waste elimination. One of them is the maintenance of communication and the regulation of co-functioning between different parts of the nephron through exosomal mRNA and miRNA reuptake by recipient cells (Dimov et al., 2009; Keller et al., 2007; Pisitkun et al., 2006). Urinary exosomes could provide a rich source of disease biomarkers, especially for kidney diseases. It has already been shown that a decrease in urinary exosomal aquaporin-1 can be a marker of renal ischemiareperfusion injury and that urinary exosomes can provide biomarkers of kidney dysfunction in recipients after renal transplantation (Alvarez et al., 2013; Sonoda et al., 2009). Lowabundance urinary proteins, mRNAs, miRNAs and transcription factors with potential pathophysiological significance can be obtained by exosome isolation (Dimov et al., 2009; Fang et al., 2013).
Urinary mtDNA

mtDNA is a circular, double-stranded DNA structure, consisting of 37 genes, which are transcribed into mRNA coding for proteins that are involved in mitochondria's main function: oxidative phosphorylation, transfer-RNA, and ribosomal-RNA (Turnbull et al., 1999). When renal mitochondria suffer an injury and their integrity is compromised, for instance, because of hyperfiltration or renal hypoxia, mtDAMPs might be released into the urine and as such can serve as markers of renal mitochondrial injury. These molecular patterns of released mtDNAs also influence oxidative injury and inflammation at distant sites via Toll-like receptor signaling (Pinti et al., 2012). It is known that ischemic renal tubular injury is associated with mitochondrial damage and dysfunction both in the initiation and recovery phases in ischemia-reperfusion induced acute kidney injury (AKI) (Jassem et al., 2002; Weinberg et al., 2000). Urinary mtDNA correlates with the progression of renal dysfunction in patients with AKI after cardiac surgery (Whitaker et al., 2015). Moreover, urinary mtDNA copy numbers are higher in patients with essential and renovascular hypertension than in healthy controls. It was also reported that urinary mtDNA copy numbers in these patients correlate with renal injury and dysfunction markers due to the mitochondrial injury present in hypertension-induced renal damage (Eirin et al., 2016). Furthermore, cancer-associated mtDNA mutations have been identified in body fluids, including urine of patients with bladder and prostate cancer (Fliss et al., 2000; Jerónimo et al., 2001). Also, exosomes have been shown to carry mtDNA in some cases, and a decrease in urinary exosomal mtDNA has been linked to chronic kidney disease in diabetic patients (Sharma et al., 2013).

\section{Urinary RNA species}

Cell-free RNA of both plasmatic-transrenal and postrenal origin was found in urine. However, more studies focus on RNA released into the urine postrenally, via apoptosis, necrosis, oncosis, and active secretion, as a part of vesicles. Studies pointing to the detection of survirin, cytokeratin 20, mucin 7, and Ki-67 mRNAs in the urine of patients suffering from bladder cancer and various urinary tract infections prove that the apoptosis and necrosis of the cells of the urogenital tract is one of the main sources of urinary RNA (Bryzgunova and Laktionov, 2015; Menke and Warnecke, 2004; Pu et al., 2008).

The transformation of urinary mRNAs into diagnostic markers remains challenging because human urine contains a wide set of RNA hydrolyzing enzymes (these are: RNases 2 and 1, RNase C and $\mathrm{U}$ with a $\mathrm{pH}$ optimum of 8.5 and 7.0, respectively, as RNase 7, UL, US, UpI-1, and UpI-2). On one hand, RNA is susceptible to degradation by endonucleases similarly to DNA. Nevertheless, miRNAs are smaller than mRNAs and their ability to resist/escape nucleases is higher. Such protected molecules could prove to be more effective and used as biomarkers. For example, miRNAs can form complexes with biopolymers, which protect them, bind argonaute proteins, or be released from cells via exosomes containing a proportion of urinary scaRNAs (small Cajal bodyspecific RNAs), snoRNAs (small nucleolar RNAs), snRNAs (small nuclear RNA), piRNAs (Piwi-interacting RNA), and miRNAs. From this viewpoint, miRNA is of higher diagnostic value than mRNA ( $\mathrm{Li}$ et al., 2014; Miranda et al., 2010). A differential expression of urinary miRNAs has been shown in several renal diseases. For example, in IgA nephropathy, miR-21 and miR-29 are downregulated and miR-93 is upregulated in the urine of patients when compared to healthy controls. A panel of 27 differentially regulated urinary miRNAs that varied with diabetic nephropathy progression has also been described. It is yet unclear, whether the majority of miRNAs is exosome or argonaute bound. It has been shown that 
urinary miR-16 and miR-192 are associated with exosomes, while miR-16 and miR192 are present in association with the argonaute protein AGO2 (Argyropoulos et al., 2013; Beltrami et al., 2015; Simpson et al., 2016; Wang et al., 2012). Thus, urinary DNA or RNA might represent a valuable information about the health condition of the kidneys as well as other tissues.

\section{Urinary CNA in clinical studies}

Variety of renal pathologies are linked with increased nucleic acids in the urine (summarized in Table 1). For example, the $Y$ chromosome-specific sequences were detected in the urine of female kidney transplant patients who had received kidneys from the male donors. The presence of $\mathrm{Y}$ chromosome-specific sequences was confirmed in 21 out of 25 cases. Donor-derived urinary DNA might appear via forms of cell death or trauma, which includes periods of graft rejection. The analysis has also shown that transplant-derived DNA exceeded 900 copies per ml of urine after surgery, but decreased to undetectable levels within the next 7 days. Additionally, the urine samples of female patients, who experienced some degree of graft rejection, and had received a male kidney contained elevated transplant-specific cell-free DNA concentrations up to several thousand copies. This concentration dropped to barely detectable levels after a successful treatment within 11 days of initial rejection (Zhong et al., 2001). These results suggest that free nucleic acids in the urine could be potentially used for monitoring of the graft rejection.

Another example shows the number of mtDNA molecules in the urine is elevated in patients with both essential and renovascular hypertension (Eirin et al., 2016). Also, the urinary COX3 (cyclooxygenase 3) and ND1 (nicotinamide adenine dinucleotide (NADH) dehydrogenase subunit-1) inversely correlated with the estimated glomerular filtration (eGFR) rate and positively correlated with serum creatinine, urinary NGAL (neutrophil gelatinase-associated lipocalin) and KIM-1 in both hypertensive groups. In the renovascular group, the number of urinary COX3 and ND1 copies positively correlated with cortical oxygenation and fractional hypoxia. Thus specific mtDNA concentrations correlated with the severity of renal injury and dysfunction (Eirin et al., 2016). Since mitochondrial injury plays a role in the pathogenesis of kidney damage in hypertension and ischemic nephropathy, this was not surprising. Nevertheless, the study found the urinary number of mtDNA copies for COX3 and ND1 to be significantly higher in the renovascular group when compared to patients with essential hypertension. After 3 months of appropriate therapy, the change in serum creatinine and eGFR correlated well with the change in urinary mtDNA concentrations (Eirin et al., 2016). Specific sequences of free mitochondrial nucleic acids could be thus used for distinguishing between essential and secondary hypertension and adjustment of the treatment accordingly.

A type I membrane glycoprotein (B7-1) belonging to the immunoglobulin superfamily, is associated with podocyte-specific genes as is NPHS1. Its expression is increased within glomerular epithelial cells in glomerular kidney diseases. As such, urinary mRNA levels of B7-1 and NPHS1 represent potential specific gene candidates in patients suffering from proliferative and nonproliferative glomerular kidney disease. The urinary sediment of patients with glomerular diseases contained higher concentrations of both of these mRNAs when compared to those of healthy controls (Navarro-Muñoz et al., 2011). A variety of other states are related to podocyte injury and loss, for example during the course of diabetic nephropathy. The expressions of podocyte-associated molecules, such as nephrin, podocin, synaptopodin, WT-1, and $\alpha$-actinin- 4 , were analysed in the urine sediments of patients with diabetic nephropathy. The expression of all mentioned candidates is higher in patients than in healthy controls and correlates with baseline renal function. The expression of markers significantly decreased in the urine of diabetic patients after treatment, suggesting that a serial measurement of urinary podocyte markers may have a value in the monitoring of the response to treatment of such patients (Wang et al., 2007, 2008).

Increase in plasmatic extracellular DNA, RNA, especially miRNAs was confirmed in tumours of various tissues including the kidneys. However, the urinary CNA in renal or uropoetic cancer was studied only in a small number of studies. One of the most common kidney tumours is renal cell carcinoma (RCC). DNA fragments of brain type fatty acid binding protein (B-FABP) was found increased in urine samples of patients with RCC (Teratani et al., 2007). After removal of the tumour, the levels of DNA fragments dropped to undetectable concentrations. Another study identified urothelial carcinoma associated 1 (UCA1) as a potential candidate marker for the bladder cancer. UCA1 is a novel noncoding RNA molecule that plays a regulatory role in bladder cancer cell proliferation and could prove to be a sensitive marker for bladder cancer detection in clinical use (Wang, 2006).

The above-mentioned studies prove that urine is an interesting biofluid for the detection of renal diseases, monitoring of disease progression or distinguishing between primary and secondary causes of hypertension. It might also help for early detection of malignant tumours, especially the bladder tumour. Although the urinary CNAs as a whole are not specific, the more detailed analysis of such free nucleic acids might become a reliable method for the assessment of early uropoetic and renal impairment. On top of that, the non-invasive and easy collection of urine could become a point-of-care testing in the near future.

\section{Conclusion}

Circulating nucleic acids have been isolated from almost all types of biological fluids, including urine. Since their discovery in circulation in 1948 by Mantel and Metais, the field of CNA has advanced steadily. Their potential use as biomarkers of diseases made them an attractive research target. Several studies have already shown increased concentrations of urinary CNA in animal

Table 1

An overview of urinary nucleic acid markers associated with diseases in patients.

\begin{tabular}{|c|c|c|c|c|}
\hline Marker & Method & Disease & Species & Citation \\
\hline mtDNA copy number & Quantitative real-time PCR & Renal injury following cardiopulmonary bypass & Human & Whitaker et al. (2015) \\
\hline Urinary DNA of donor origin & PCR & Acute rejection in renal transplant patients & Human & Zhang et al. (2001) \\
\hline TSPAN13-to-S100A9 ratio & Quantitative real-time PCR & Prostate cancer & Human & Yan et al. (2015) \\
\hline mtDNA copy number & Quantitative real-time PCR & Renovascular hypertensia & Human & Eirin et al. (2016) \\
\hline Urinary mRNA of UCA1 & Reverse-transcription PCR & Bladder transitional cell carcinoma & Human & Wang (2006) \\
\hline NephrRNA and PodRNA & Quantitative real-time PCR & Acquired proteinuric diseases & Human & Szeto et al. (2005) \\
\hline Urinary mRNA of B7-1 and NPHS1 & Quantitative real-time PCR & Glomerular kidney disease & Human & Navarro-Muñoz et al. (2011) \\
\hline VEGF mRNA & Quantitative real-time PCR & Clear cell renal cell carcinoma & Human & Zhao et al. (2015) \\
\hline Urinary mRNA of podocyte-associated molecules & Quantitative real-time PCR & Diabetic nephropathy & Human & Wang et al. (2007) \\
\hline miR-146a & Quantitative real-time PCR & Lupus nephritis & Human & Perez-Hernandez et al. (2015) \\
\hline
\end{tabular}


models of various renal diseases. The clinical studies performed so far point to the same phenomenon in patients. There are still some difficulties that need to be overcome in the emerging field of urinary CNA. Mainly, technical issues are of major concern. However, as the new biomarkers of great diagnostic potential are much needed in nephrology and urology, it is anticipated that these issues will be solved in the near future and candidate CNA biomarkers will be indispensably used as a diagnostic tool of renal diseases.

\section{Conflict of interests}

The authors have no conflict of interests to declare.

\section{Acknowledgements}

This work was supported by the Comenius University research grant for young investigators No. UK 56/2016 and Ministry of education, science, research and sport of the Slovak Republic No. VEGA 2/0105/15 and VEGA 1/2034/18.

\section{References}

Adams, D.H., Macintosh, A.A.G., 1985. Studies on the cytosolic DNA of chick embryo fibroblast cells and its uptake by recipient cultured cells. Int. J. Biochem. 17, 1041-1051.

Adams, D.H., Diaz, N., Gahan, P.B., 1997. In vitro stimulation by tumour cell media of [3H]-thymidine incorporation by mouse spleen lymphocytes. Cell Biochem. Funct. 15, 119-126.

Akers, J.C., Gonda, D., Kim, R., Carter, B.S., Chen, C.C., 2013. Biogenesis of extracellular vesicles (EV): exosomes, microvesicles, retrovirus-like vesicles, and apoptotic bodies. J. Neurooncol. 113, 1-11.

Alvarez, S., Suazo, C., Boltansky, A., Ursu, M., Carvajal, D., Innocenti, G., et al., 2013. Urinary exosomes as a source of kidney dysfunction biomarker in renal transplantation. Transplant. Proc. 45, 3719-3723.

Anker, P., Stroun, M., 1972. Bacterial ribonucleic acid in the frog brain after a bacterial peritoneal infection. Science (New York, NY) 178, 621-623.

Anker, P., Stroun, M., Maurice, P.A., 1975. Spontaneous release of DNA by human blood lymphocytes as shown in an in vitro system. Cancer Res. 35, 2375-2382.

Anker, P., Stroun, M., Maurice, P.A., 1976. Spontaneous extracellular synthesis of DNA released by human blood lymphocytes. Cancer Res. 36, 2832-2839.

Appleby, D.W., Modak, S.P., 1977. DNA degradation in terminally differentiating len fiber cells from chick embryos. Proc. Natl. Acad. Sci. U. S. A. 74, 5579-5583.

Argyropoulos, C., Wang, K., McClarty, S., Huang, D., Bernardo, J., Ellis, D., et al., 2013. Urinary microRNA profiling in the nephropathy of type 1 diabetes. PLoS One 8 e54662-e54662.

Arroyo, J.D., Chevillet, J.R., Kroh, E.M., Ruf, I.K., Pritchard, C.C., Gibson, D.F., et al., 2011. Argonaute 2 complexes carry a population of circulating microRNAs independent of vesicles in human plasma. Proc. Natl. Acad. Sci. U. S. A. 108 5003-5008.

Beiter, T., Fragasso, A., Hartl, D., Nieß, A.M., 2015. Neutrophil extracellular traps: a walk on the wild side of exercise immunology. Sports Med. 45, 625-640.

Beltrami, C., Clayton, A., Newbury, L., Corish, P., Jenkins, R., Phillips, A., et al., 2015. Stabilization of urinary microRNAs by association with exosomes and argonaute 2 protein. Non-Coding RNA 1, 151-166.

Bickerstaff, M.C., Botto, M., Hutchinson, W.L. Herbert, J., Tennent, G.A., Bybee, A., et al., 1999. Serum amyloid P component controls chromatin degradation and prevents antinuclear autoimmunity. Nat. Med. 5, 694-697.

Botezatu, I., Serdyuk, O., Potapova, G., Shelepov, V., Alechina, R., Molyaka, Y., et al. 2000. Genetic analysis of DNA excreted in urine: a new approach for detecting specific genomic DNA sequences from cells dying in an organism. Clin. Chem. 46, 1078-1084.

Brinkmann, V., Reichard, U., Goosmann, C., Fauler, B., Uhlemann, Y., Weiss, D.S., et al., 2004. Neutrophil extracellular traps kill bacteria. Science 303, 1532-1535.

Bryzgunova, O.E., Laktionov, P.P., 2015. Extracellular nucleic acids in urine: sources, structure, diagnostic potential. Acta Naturae 7, 48-54.

Chan, A.K.C., Chiu, R.W.K., Lo, Y.M.D., 2003. Cell-free nucleic acids in plasma, serum and urine: a new tool in molecular diagnosis. Ann. Clin. Biochem. 40,122-130.

Chim, S.S.C., Shing, T.K.F., Hung, E.C.W., Leung, T.-Y., Lau, T.-K., Chiu, R.W.K., et al., 2008. Detection and characterization of placental microRNAs in maternal plasma. Clin. Chem. 54, 482-490.

Chiu, R.W.K., Chan, L.Y.S., Lam, N.Y.L., Tsui, N.B.Y., Ng, E.K.O., Rainer, T.H., et al., 2003. Quantitative analysis of circulating mitochondrial DNA in plasma. Clin. Chem. 49, 719-726.

Clark, S.R., Ma, A.C., Tavener, S.A., McDonald, B., Goodarzi, Z., Kelly, M.M., et al., 2007. Platelet TLR4 activates neutrophil extracellular traps to ensnare bacteria in septic blood. Nat. Med. 13, 463-469.

Cooper, E.J., Trautmann, M.L., Laskowski, M., 1950. Occurrence and distribution of an inhibitor for deoxyribonuclease in animal tissues. Exp. Biol. Med. 73, 219-222.
Demers, M., Krause, D.S., Schatzberg, D., Martinod, K., Voorhees, J.R., Fuchs, T.A., et al., 2012. Cancers predispose neutrophils to release extracellular DNA traps that contribute to cancer-associated thrombosis. Proc. Natl. Acad. Sci. U. S. A. 109, 13076-13081.

de Boer, O.J., Li, X., Teeling, P., Mackaay, C., Ploegmakers, H.J., van der Loos, C.M., et al., 2013. Neutrophils, neutrophil extracellular traps and interleukin-17 associate with the organisation of thrombi in acute myocardial infarction. Thromb. Haemost. 109, 290-297.

de Buhr, N., von Köckritz-Blickwede, M., 2016. How neutrophil extracellular traps become visible. J. Immunol. Res. 2016, 1-13.

Dimov, I., Jankovic Velickovic, L., Stefanovic, V., 2009. Urinary exosomes. Sci. World J. 9, 1107-1118

Dworski, R., Simon, H.-U., Hoskins, A., Yousefi, S., 2011. Eosinophil and neutrophi extracellular DNA traps in human allergic asthmatic airways. J. Allergy Clin. Immunol. 127, 1260-1266.

Dwyer, M., Shan, Q., D'Ortona, S., Maurer, R., Mitchell, R., Olesen, H., et al., 2014. Cystic fibrosis sputum DNA has NETosis characteristics and neutrophil extracellular trap release is regulated by macrophage migration-inhibitory factor. J. Innate Immun. 6, 765-779.

Eirin, A., Saad, A., Tang, H., Herrmann, S.M., Woollard, J.R., Lerman, A., et al., 2016. Urinary mitochondrial DNA copy number identifies chronic renal injury in hypertensive patients. Hypertension 68, 401-410.

Fang, D.Y., King, H.W., Li, J.Y., Gleadle, J.M., 2013. Exosomes and the kidney: blaming the messenger. Nephrology (Carlton, Vic) 18, 1-10.

Fatouros, I.G., Destouni, A., Margonis, K., Jamurtas, A.Z., Vrettou, C., Kouretas, D., et al., 2006. Cell-free plasma DNA as a novel marker of aseptic inflammation severity related to exercise overtraining. Clin. Chem. 52, 1820-1824.

Fleischhacker, M., Schmidt, B., Weickmann, S., Fersching, D.M.I., Leszinski, G.S. Siegele, B., et al., 2011. Methods for isolation of cell-free plasma DNA strongly affect DNA yield. Clin. Chim. Acta 412, 2085-2088.

Fliss, M.S., Usadel, H., Caballero, O.L., Wu, L., Buta, M.R., Eleff, S.M., et al., 2000. Facile detection of mitochondrial DNA mutations in tumors and bodily fluids. Science (New York, NY) 287, 2017-2019.

Frittitta, L., Camastra, S., Baratta, R., Costanzo, B.V., D’Adamo, M., Graci, S., et al., 1999. A soluble PC-1 circulates in human plasma: relationship with insulin resistance and associated abnormalities. J. Clin. Endocrinol. Metab. 84, 36203625.

Gahan, P.B., Wyndaele, R., Mantell, S., Boggetti, B., 2003. Evidence that direct DNA uptake through cut shoots leads to genetic transformation of Solanum aviculare Forst. Cell Biochem. Funct. 21, 11-17.

Gahan, P.B., Anker, P., Stroun, M., 2008. Metabolic DNA as the origin of spontaneously released DNA? Ann. N. Y. Acad. Sci. 1137, 7-17.

Gal, S., Fidler, C., Turner, S., Lo, Y.M., Roberts, D.J., Wainscoat, J.S., 2001. Detection of Plasmodium falciparum DNA in plasma. Ann. N. Y. Acad. Sci. 945, 234-238.

García-Olmo, D.C., Ruiz-Piqueras, R., García-Olmo, D., 2004. Circulating nucleic acids in plasma and serum (CNAPS) and its relation to stem cells and cancer metastasis: state of the issue. Histol. Histopathol. 19, 575-583.

Garcia Moreira, V., de la Cera Martinez, T., Gago Gonzalez, E., Prieto Garcia, B., Alvarez Menendez, F.V., 2006. Increase in and clearance of cell-free plasma DNA in hemodialysis quantified by real-time PCR. Clin. Chem. Lab. Med. 44, 1410-1415.

Gauthier, V.J., Tyler, L.N., Mannik, M., 1996. Blood clearance kinetics and liver uptake of mononucleosomes in mice. J. Immunol. 156, 1151-1156.

Gezer, U., Özgür, E., Cetinkaya, M., Isin, M., Dalay, N., 2014. Long non-coding RNAs with low expression levels in cells are enriched in secreted exosomes. Cell Biol. Int. 38, 1076-1079.

Griffith, F., 1928. The significance of pneumococcal types. J. Hyg. 27 113-113.

Guescini, M., Guidolin, D., Vallorani, L., Casadei, L., Gioacchini, A.M., Tibollo, P., et al., 2010. C2C12 myoblasts release micro-vesicles containing mtDNA and proteins involved in signal transduction. Exp. Cell Res. 316, 1977-1984.

Gupta, A., Hasler, P., Gebhardt, S., Holzgreve, W., Hahn, S., 2006. Occurrence of neutrophil extracellular DNA traps (NETs) in pre-eclampsia: a link with elevated levels of cell-free DNA? Ann. N. Y. Acad. Sci. 1075, 118-122.

Halicka, H.D., Bedner, E., Darzynkiewicz, Z., 2000. Segregation of RNA and separate packaging of DNA and RNA in apoptotic bodies during apoptosis. Exp. Cell Res. 260, 248-256.

Holdenrieder, S., Stieber, P., 2004. Apoptotic markers in cancer. Clin. Biochem. 37, 605-617.

Jahr, S., Hentze, H., Englisch, S., Hardt, D., Fackelmayer, F.O., Hesch, R.D., et al., 2001. DNA fragments in the blood plasma of cancer patients: quantitations and evidence for their origin from apoptotic and necrotic cells. Cancer Res. 61,16591665 .

Jassem, W., Fuggle, S.V., Rela, M., Koo, D.D.H., Heaton, N.D., 2002. The role of mitochondria in ischemia/reperfusion injury. Transplantation 73, 493-499.

Jerónimo, C., Nomoto, S., Caballero, O.L., Usadel, H., Henrique, R., Varzim, G., et al., 2001. Mitochondrial mutations in early stage prostate cancer and bodily fluids. Oncogene 20, 5195-5198

Johnstone, R.M., Mathew, A., Mason, A.B., Teng, K., 1991. Exosome formation during maturation of mammalian and avian reticulocytes: evidence that exosome release is a major route for externalization of obsolete membrane proteins. J. Cell. Physiol. 147, 27-36.

Keller, S., Rupp, C., Stoeck, A., Runz, S., Fogel, M., Lugert, S., et al., 2007. CD24 is a marker of exosomes secreted into urine and amniotic fluid. Kidney Int. 72 $1095-1102$

Kopreski, M.S., Benko, F.A., Kwak, L.W., Gocke, C.D., 1999. Detection of tumor messenger RNA in the serum of patients with malignant melanoma. Clin. Cancer Res. 5, 1961-1965. 
Leon, S.A., Shapiro, B., Sklaroff, D.M., Yaros, M.J., 1977. Free DNA in the serum of cancer patients and the effect of therapy. Cancer Res. 37, 646-650.

Li, J.Z., Steinman, C.R., 1989. Plasma DNA in systemic lupus erythematosus. Characterization of cloned base sequences. Arthritis Rheum. 32, 726-733.

Li, M., Zeringer, E., Barta, T., Schageman, J., Cheng, A., Vlassov, A.V., 2014. Analysis of the RNA content of the exosomes derived from blood serum and urine and its potential as biomarkers. Philos. Trans. R Soc. Lond. B Biol. Sci. 369 (1652), 20130502.

Lo, Y.M., Corbetta, N., Chamberlain, P.F., Rai, V., Sargent, I.L., Redman, C.W., et al., 1997. Presence of fetal DNA in maternal plasma and serum. Lancet 350, 485487.

Lo, Y.M., Tein, M.S., Pang, C.C., Yeung, C.K., Tong, K.L., Hjelm, N.M., 1998. Presence of donor-specific DNA in plasma of kidney and liver-transplant recipients. Lancet 351, 1329-1330.

Lo, Y.M., Chan, L.Y., Lo, K.W., Leung, S.F., Zhang, J., Chan, A.T., et al., 1999a. Quantitative analysis of cell-free Epstein-Barr virus DNA in plasma of patients with nasopharyngeal carcinoma. Cancer Res. 59, 1188-1191.

Lo, Y.M., Zhang, J., Leung, T.N., Lau, T.K., Chang, A.M., Hjelm, N.M., 1999b. Rapid clearance of fetal DNA from maternal plasma. Am. J. Hum. Genet. 64, 218-224.

Lo, Y.M., Rainer, T.H., Chan, L.Y., Hjelm, N.M., Cocks, R.A., 2000. Plasma DNA as a prognostic marker in trauma patients. Clin. Chem. 46, 319-323.

Lote, C., 2000. Principles of Renal Physiology. Springer, Dordrecht.

McDonald, B., Urrutia, R., Yipp Bryan, G., Jenne Craig, N., Kubes, P., 2012. Intravascular neutrophil extracellular traps capture bacteria from the bloodstream during sepsis. Cell Host Microbe 12, 324-333.

Mehra, N., Penning, M., Maas, J., van Daal, N., Giles, R.H., Voest, E.E., 2007. Circulating mitochondrial nucleic acids have prognostic value for survival in patients with advanced prostate cancer. Clin. Cancer Res. 13, 421-426.

Menke, T.B., Warnecke, J.M., 2004. Improved conditions for isolation and quantification of RNA in urine specimens. Ann. N. Y. Acad. Sci. 1022, 185-189.

Miranda, K.C. Bond, D.T., McKee, M., Skog. J., Păunescu, T.G., Da Silva, N., et al., 2010. Nucleic acids within urinary exosomes/microvesicles are potential biomarkers for renal disease. Kidney Int. 78, 191-199.

Mittra, I., Nair, N.K., Mishra, P.K., 2012. Nucleic acids in circulation: are they harmful to the host? J. Biosci. 37, 301-312.

Montecalvo, A., Larregina, A.T., Shufesky, W.J., Stolz, D.B., Sullivan, M.L.G., Karlsson, J. M., et al., 2012. Mechanism of transfer of functional microRNAs between mouse dendritic cells via exosomes. Blood 119, 756-766.

Nadano, D., Yasuda, T., Kishi, K., 1993. Measurement of deoxyribonuclease I activity in human tissues and body fluids by a single radial enzyme-diffusion method. Clin. Chem. 39, 448-452.

Nagata, S., Nagase, H., Kawane, K., Mukae, N., Fukuyama, H., 2003. Degradation of chromosomal DNA during apoptosis. Cell Death Differ. 10, 108-116.

Nagata, S., 2005. DNA degradation in development and programmed cell death. Annu. Rev. Immunol. 23, 853-875.

Navarro-Muñoz, M., Ibernon, M., Pérez, V., Ara, J., Espinal, A., López, D., et al., 2011 Messenger RNA expression of B7-1 and NPHS1 in urinary sediment could be useful to differentiate between minimal-change disease and focal segmental glomerulosclerosis in adult patients. Nephrol. Dial. Transplantat. 26, 3914-3923.

Nishimoto, S., Fukuda, D., Higashikuni, Y., Tanaka, K., Hirata, Y., Murata, C., et al., 2016. Obesity-induced DNA released from adipocytes stimulates chronic adipose tissue inflammation and insulin resistance. Sci. Adv. 2 e1501332e1501332.

O'Driscoll, L., 2007. Extracellular nucleic acids and their potential as diagnostic: prognostic and predictive biomarkers. Anticancer Res. 27, 1257-1265.

Pepys, M.B., Butler, P.J., 1987. Serum amyloid P component is the major calciumdependent specific DNA binding protein of the serum. Biochem. Biophys. Res. Commun. 148, 308-313.

Perez-Hernandez, J., Forner, M.J., Pinto, C., Chaves, F.J., Cortes, R., Redon, J., 2015 Increased urinary exosomal micrornas in patients with systemic lupus erythematosus. PLoS One 10,1-16.

Peters, D.L., Pretorius, P.J., 2011. Origin, translocation and destination of extracellular occurring DNA - a new paradigm in genetic behaviour. Clin. Chim. Acta 412, 806-811.

Pinti, M., Mussini, C., Cossarizza, A., 2012. Mitochondrial DNA: a proinflammatory 'enemy from within' during HIV infection? Cell. Death. Dis. 3 (307-307).

Pisitkun, T., Johnstone, R., Knepper, M.A., 2006. Discovery of urinary biomarkers. Mol. Cell. Proteomics 5, 1760-1771.

Pu, X.-Y., Wang, Z.-P., Chen, Y.-R., Wang, X.-H., Wu, Y.-L., Wang, H.-P., 2008. The value of combined use of survivin, cytokeratin 20 and mucin 7 mRNA for bladder cancer detection in voided urine. J. Cancer Res. Clin. Oncol. 134, 659-665.

Rainer, T.H., Wong, L.K.S., Lam, W., Yuen, E., Lam, N.Y.L., Metreweli, C., et al., 2003. Prognostic use of circulating plasma nucleic acid concentrations in patients with acute stroke. Clin. Chem. 49, 562-569.

Raptis, L., Menard, H.A., 1980. Quantitation and characterization of plasma DNA in normals and patients with systemic lupus erythematosus. J. Clin. Invest. 66, 1391-1399.

Rogers, J.C., Boldt, D., Kornfeld, S., Skinner, A., Valeri, C.R., 1972. Excretion of deoxyribonucleic acid by lymphocytes stimulated with phytohemagglutinin or antigen. Proc. Natl. Acad. Sci. U. S. A. 69, 1685-1689.

Scher, W., Friend, C., 1978. Breakage of DNA and alterations in folded genomes by inducers of differentiation in Friend erythroleukemic cells. Cancer Res. 38, 841849.

Sharma, V.K., Vouros, P., Glick, J., 2011. Mass spectrometric based analysis, characterization and applications of circulating cell free DNA isolated from human body fluids. Int. J. Mass spectrom. 304, 172-183.
Sharma, K., Karl, B., Mathew, A.V., Gangoiti, J.A., Wassel, C.L., Saito, R., et al., 2013 Metabolomics reveals signature of mitochondrial dysfunction in diabetic kidney disease. J. Am. Soc. Nephrol. 24, 1901-1912.

Shuster, A.M., Gololobov, G.V., Kvashuk, O.A., Bogomolova, A.E., Smirnov, I.V. Gabibov, A.G., 1992. DNA hydrolyzing autoantibodies. Science 256, 665-667.

Simpson, K., Wonnacott, A., Fraser, D.J., Bowen, T., 2016. MicroRNAs in diabetic nephropathy: from biomarkers to therapy. Curr. Diab. Rep. 16, 1-7.

Sonoda, H., Yokota-Ikeda, N., Oshikawa, S., Kanno, Y., Yoshinaga, K., Uchida, K., et al. 2009. Decreased abundance of urinary exosomal aquaporin-1 in renal ischemiareperfusion injury. Am. J. Physiol. Renal Physiol. 297, F1006-F1016.

Stroun, M., Anker, P., 1972. Nucleic acids spontaneously released by living frog auricles. Biochem. J. 128, 100P-101P.

Stroun, M., Anker, P., Lyautey, J., Lederrey, C., Maurice, P.A., 1987. Isolation and characterization of DNA from the plasma of cancer patients. Eur. J. Cancer Clin. Oncol. 23, 707-712.

Stroun, M., Anker, P., Maurice, P., Lyautey, J., Lederrey, C., Beljanski, M., 1989. Neoplastic characteristics of the DNA found in the plasma of cancer patients. Oncology 46, 318-322.

Surmiak, M.P., Hubalewska-Mazgaj, M., Wawrzycka-Adamczyk, K., Szczeklik, W., Musia, J., Sanak, M., 2015. Circulating mitochondrial DNA in serum of patients with granulomatosis with polyangiitis. Clin. Exp. Immunol. 181, 150-155.

Szeto, C.C., Lai, K.B., Chow, K.M., Szeto, C.Y.K., Yip, T.W.C., Woo, K.S., et al., 2005. Messenger RNA expression of glomerular podocyte markers in the urinary sediment of acquired proteinuric diseases. Clin. Chim. Acta 361, 182-190.

Tamkovich, S.N., Cherepanova, A.V., Kolesnikova, E.V., Rykova, E.Y., Pyshnyi, D.V., Vlassov, V.V., et al., 2006. Circulating DNA and DNase activity in human blood. Ann. N. Y. Acad. Sci. 1075, 191-196.

Tan, E.M., Schur, P.H., Carr, R.I., Kunkel, H.G., 1966. Deoxybonucleic acid (DNA) and antibodies to DNA in the serum of patients with systemic lupus erythematosus. J. Clin. Invest. 45, 1732-1740.

Terada, M., Nudel, U., Fibach, E., Rifkind, R.A., Marks, P.A., 1978. Changes in DNA associated with induction of erythroid differentiation by dimethyl sulfoxide in murine erythroleukemia cells. Cancer Res. 38, 835-840.

Teratani, T., Domoto, T., Kuriki, K., Kageyama, T., Takayama, T., Ishikawa, A., et al., 2007. Detection of transcript for brain-type fatty Acid-binding protein in tumor and urine of patients with renal cell carcinoma. Urology 69, 236-240.

Thakur, B.K., Zhang, H., Becker, A., Matei, I., Huang, Y., Costa-Silva, B., et al., 2014 Double-stranded DNA in exosomes: a novel biomarker in cancer detection. Cell Res. 24, 766-769.

Tsai, N.-W., Lin, T.-K., Chen, S.-D., Chang, W.-N., Wang, H.-C., Yang, T.-M., et al., 2011. The value of serial plasma nuclear and mitochondrial DNA levels in patients with acute ischemic stroke. Clin. Chim. Acta 412, 476-479.

Turchinovich, A., Weiz, L., Langheinz, A., Burwinkel, B., 2011. Characterization of extracellular circulating microRNA. Nucleic Acids Res. 39, 7223-7233.

Turnbull, D.M., Andrews, R.M., Kubacka, I., Chinnery, P.F., Lightowlers, R.N., Howell N., 1999. Reanalysis and revision of the Cambridge reference sequence for human mitochondrial DNA. Nat. Genet. 23 147-147.

Urbanelli, L., Buratta, S., Sagini, K., Ferrara, G., Lanni, M., Carla, E., 2015. Exosomebased strategies for diagnosis and therapy. Recent Pat CNS Drug Discov. 10, 10 27.

van Balkom, B.W.M., Pisitkun, T., Verhaar, M.C., Knepper, M.A., Stoorvogel, W., Kleijmeer, M.J., et al., 2011. Exosomes and the kidney: prospects for diagnosis and therapy of renal diseases. Kidney Int. 80, 1138-1145.

van der Vaart, M., Pretorius, P.J., 2008. Circulating DNA. Ann. N. Y. Acad. Sci. 1137, 18 26.

Valadi, H., Ekström, K., Bossios, A., Sjöstrand, M., Lee, J.J., Lötvall, J.O., 2007. Exosomemediated transfer of mRNAs and microRNAs is a novel mechanism of genetic exchange between cells. Nat. Cell Biol. 9, 654-659.

Wang, G., Lai, F.M.M., Tam, L.S., Li, K.M., Lai, K.B., Chow, K.M., et al., 2007. Messenge RNA expression of podocyte-associated molecules in urinary sediment of patients with lupus nephritis. J. Rheumatol. 34, 2358-2364.

Wang, G., Lai, F.M.M., Lai, K.B., Chow, K.M., Kwan, B.C.H., Li, P.K.T., et al., 2008. Urinary messenger RNA expression of podocyte-associated molecules in patients with diabetic nephropathy treated by angiotensin-converting enzyme inhibitor and angiotensin receptor blocker. Eur. J. Endocrinol. 158, 317-322.

Wang, K., Zhang, S., Weber, J., Baxter, D., Galas, D.J., 2010. Export of microRNAs and microRNA-protective protein by mammalian cells. Nucleic Acids Res. 38, 7248 7259.

Wang, G., Kwan, B.C.-H., Lai, F.M.-M., Chow, K.-M., Li, P.K.-T., Szeto, C.-C., 2012. Urinary miR-21, miR-29, and miR-93: novel biomarkers of fibrosis. Am. J. Nephrol. 36, 412-418.

Wang, X.S., 2006. Rapid identification of UCA1 as a very sensitive and specific unique marker for human bladder carcinoma. Clin. Cancer Res. 12, 4851-4858.

Weil, M., Raff, M.C., Braga, V.M., 1999. Caspase activation in the terminal differentiation of human epidermal keratinocytes. Curr. Biol. 9, 361-364.

Weinberg, J.M., Venkatachalam, M.A., Roeser, N.F., Nissim, I., 2000. Mitochondrial dysfunction during hypoxia/reoxygenation and its correction by anaerobic metabolism of citric acid cycle intermediates. Proc. Natl. Acad. Sci. U. S. A. 2826 2831 .

Wenceslau, C.F., McCarthy, C.G., Szasz, T., Spitler, K, Goulopoulou, S., Webb, R.C., et al., 2014. Mitochondrial damage-associated molecular patterns and vascular function. Eur. Heart J. 35, 1172-1177.

Whitaker, R.M., Stallons, L.J., Kneff, J.E., Alge, J.L., Harmon, J.L., Rahn, J.J., et al., 2015 Urinary mitochondrial DNA is a biomarker of mitochondrial disruption and renal dysfunction in acute kidney injury. Kidney Int. 88, 1336-1344. 
Yan, C., Kim, Y.H., Kang, H.W., Seo, S.P., Jeong, P., Lee, I.S., et al., 2015. Urinary nucleic acid TSPAN13-to-S100A9 ratio as a diagnostic marker in prostate cancer. J. Korean Med. Sci. 30, 1784-1792.

Yang, H.J., Liu, V.W.S., Tsang, P.C.K., Yip, A.M.W., Tam, K.F., Wong, L.C., et al., 2004 Quantification of human papillomavirus DNA in the plasma of patients with cervical cancer. Int. J. Gynecol. Cancer 14, 903-910.

Yasuda, T., Nadano, D., Awazu, S., Kishi, K., 1992. Human urine deoxyribonuclease II (DNase II) isoenzymes: a novel immunoaffinity purification, biochemical multiplicity, genetic heterogeneity and broad distribution among tissues and body fluids. Biochim. Biophys. Acta 1119, 185-193.

Yousefi, S., Mihalache, C., Kozlowski, E., Schmid, I., Simon, H.U., 2009. Viable neutrophils release mitochondrial DNA to form neutrophil extracellular traps. Cell Death Differ. 16, 1438-1444.
Zachariah, R.R., Schmid, S., Buerki, N., Radpour, R., Holzgreve, W., Zhong, X., 2008. Levels of circulating cell-free nuclear and mitochondrial DNA in benign and malignant ovarian tumors. Obstet. Gynecol. 112, 843-850.

Zhang, Z., Ohkohchi, N., Sakurada, M., Mizuno, Y., Miyagi, T., Satomi, S., et al., 2001. Diagnosis of acute rejection by analysis of urinary DNA of donor origin in renal transplant recipients. Transplant. Proc. 33, 380-381.

Zhao, A., Péoch, M., Cottier M. I. Genin, C., Mottet, N., Li, G., 2015. Cell-free RNA content in urine as a possible molecular diagnostic tool for clear cell renal cell carcinoma. Int. J. Cancer 136, 2610-2615.

Zhong, X.Y., Hahn, D., Troeger, C., Klemm, A., Stein, G., Thomson, P., et al., 2001. Cellfree DNA in urine: a marker for kidney graft rejection, but not for prenatal diagnosis? Ann. N. Y. Acad. Sci. 945, 250-257. 